DOE/NASA/20485-9

NASA TM-81769

\title{
Comparison of Photovoltaic Cell Temperatures in Modules Operating with Exposed and Enclosed Back Surfaces
}

David Namkoong and Frederick F. Simon

National Aeronautics and Space Administration Lewis Research Center

May 1981

Eneng papy

NUG 131981

Prepared for

U.S. DEPARTMENT OF ENERGY

Conservation and Renewable Energy

Division of Solar Thermal Energy Systems 


\section{NOTICE}

This report was prepared to document work sponsored by the United States Government Neither the United States nor its agent, the United States Department of Energy. nor any Federal employees. nor any of their contractors, subcontractors or their employees, makes any warranty, express or implied, or assumes any legal liability or responsibility for the accuracy, completeness, or usefulness of any information. apparatus. product or process disclosed, or represents that its use would not infringe privately owned rights 


\section{Comparison of Photovoltaic Cell Temperatures in Modules Operating with Exposed and Enclosed Back Surfaces}

David Namkoong and Frederick F. Simon

National Aeronautics and Space Administration

Lewis Research Center

Cleveland, Ohio 44135

May 1981

Work performed for

U.S. DEPARTMENT OF ENERGY

Conservation and Renewable Energy

Division of Solar Thermal Energy Systems

Washington, D.C. 20545

Under Interagency Agreement DE-Al01-79ET20485 


\title{
COMPARISON OF PHOTOVOL TAIC CELL TEMPERATURES
}

IN MODULES OPERATING WITH EXPOSED AND

\author{
ENCL OSED BACK SURFACES \\ by David Namkoong and Frederick F. Simon \\ National Aeronautics and Space Administration \\ Lewis Research Center \\ Cleveland, Ohio 44135
}

\section{SUMMARY}

Power ratings of photovoltaic modules have been based on a common cell temperature. Under any given climatic condition, however, module cell temperature will vary with the module design. Since the cell power output is inversely proportional to its temperature, module performance can be significantly affected. A more realistic basis on which to measure and compare power rating is a module test at the temperature that the photovoltaic cell would reach when operating under a set of standardized environmental conditions.

The Jet Propulsion Laboratory (JPL) has proposed such a set of environmental conditions. The resulting cell temperature value has been termed the nominal operating cell temperature (NOCT). Recognizing that any particular set of climatic conditions would occur rarely, JPL has measured the effect on cell temperature of deviations from the standardized conditions - within specified limits. Within these limits a correction factor can be applied to the measured cell temperature to obtain the NOCT.

The NOCT concept of determining cell temperature was tested at JPL for four different module designs mounted openly (unenclosed). The same module designs were tested at the NASA Lewis Research Center to verify the applicability of the NOCT approach at another location. The results indicated an agreement between the two locations of within $21 / 2^{\circ} \mathrm{C}$ for each of the four module designs.

The NOCT procedure, though formulated originally for modules with both surfaces exposed to the elements, was also investigated for modules with the back surface enclosed (as may apply when installed on a roof). These modules were also tested with and without insulation within the enclosure volume.

The NOCT procedure was found not to be applicable to the enclosed configurations. The air pockets and the thermal mass of the enclosed volume produced a continuing transient condition that made repeatable results most unlikely. Generally, the enclosed modules had higher cell temperatures than the open modules, and insulated modules higher than noninsulated ones. The severest performance loss - when translated from cell temperatures - was 17.5 percent for one enclosed, insulated module as compared to that module mounted openly.

\section{INTRODUCTION}

Power ratings of photovoltaic modules have been based on a common cell temperature. Often the merits of modules have been judged by comparing ratings obtained in such a manner. In actual use, however, modules must 
operate in an environmental setting; and in a given setting, module cell temperature will vary with the module design. Since the cell power output is inversely proportional to its temperature, module performance can be significantly affected. A more realistic basis on which to measure and compare power rating is a module test at the temperature that the photovoltaic cell would reach when operating under a given set of environmental conditions that would act as a standard. The cell temperature measured under this set of conditions has been termed the nominal operating cell temperature (NOCT). The standardized conditions, termed the nominal terrestrial environment (NTE) by JPL, are defined as

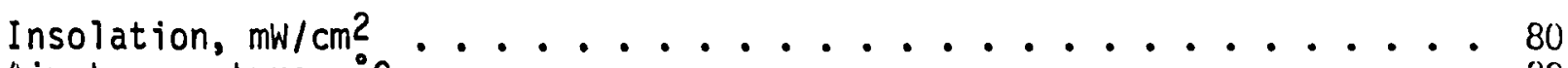

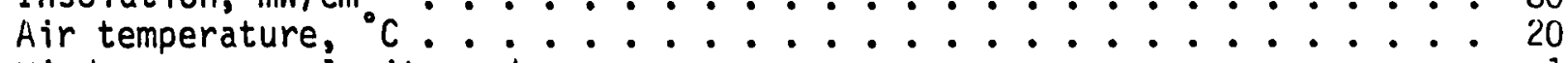

Wind average velocity, $\mathrm{m} / \mathrm{s}$. . . . . . . . . . . . . . . . 1

Mounting ................ tilted, open back, open circuit

Recognizing that any particular set of climatic conditions would occur rarely, JPL developed correction factors - based on data - for deviations from the set of standardized conditions. As long as a climatic parameter ranged with in specified limits, the cell temperature could be measured and corrected to obtain its NOCT value. The NOCT test procedure is described more fully in the appendix to this report.

The NOCT procedure, having been developed at JPL, had been tested only at that location. If the test is to have wide applicability, as intended, the results should be nearly identical at any test site (with in the specified environmental constraints). To test the procedure in a different environmental setting, JPL requested the Lewis Research Center to test several modules of different construction in the Systems Test Facility (STF).

The test modules consisted of one module randomly chosen from each of four manufacturers who supplied modules for the DOE/JPL block II module procurement (ref. 1). The four designs spanned a wide range of cell and module sizes, terminal designs, and materials.

The NOCT procedure was tested at JPL on unenclosed photovoltaic modules where the back surface of the module, as well as the front, was exposed to cooling influences. There are applications, however, where cooling of the back surface may be restricted, such as module installation flush-mounted to the roof. This report, in addition to verifying the NOCT procedure for unenclosed (openback) modules, extends the NOCT concept to enclosed modules. The enclosure design, which eliminates ambient air cooling of the back surface, was tested with and without thermal insulation with in the enclosure.

The tests and the module configurations used for such tests are summarized as follows:

(1) Verification of the JPL procedure of the NOCT at the Lewis Research Center. The modules used for the verification (the front and back surfaces exposed to ambient air cooling) are identified in the report as configuration I.

(2) Extension of the NOCT procedure to modules with the back surface enclosed to ascertain the resulting increase in cell temperature. Enclosed modules with no thermal insulation are identified as configuration II. Enclosed modules thermally insulated are identified as configuration III. 


\section{TEST PROCEDURE}

The modules were tested in an open-circuit condition. The instrumentation and test procedure used were generally as specified in the appendix.

\section{Test Hardware and Cell Temperature Measurement}

Table I presents the physical characteristics of the modules tested. Detailed characteristics of these modules are presented in reference 2 . The modules are shown in figures 1 to 4 . Two cell and two substrate thermocouples were installed for each module. The thermocouples were type $T$ (copper constantan) - 36 gage for the cells and 26 gage for the substrate surface. The cell thermocouples were soft-soldered to the cells. The substrate thermocouples were epoxied to the surface. The same four modules and cell temperature measurements were used in the NOCT tests of the three configurations. In configuration II and III tests, the module back was enclosed as shown in figure 5. The enclosure was a wooden box - uninsulated for configuration II, insulated with $10-\mathrm{cm}(4-\mathrm{in}$.$) of styrofoam within the enclosure for configura-$ tion III. A thermocouple was placed at the back inside surface of the enclosure box so as to measure the temperature difference between the solar cell and the enclosure back surface.

Two $1.2-\mathrm{m}$ by $2.7-\mathrm{m}$ (4-ft by $9-\mathrm{ft}$ ) frames were used for the tests. Each frame supported two 1.2-m by 1.2-m (4-ft by 4-ft) panels, each panel dedicated to one module (fig. 6). Aluminum sheets painted flat black were installed in those areas not covered by the module. The modules were inclined at $53^{\circ}$, which was within $3^{\circ}$ of being normal to the Sun at solar noon for September. The four modules were tested simultaneousiy. In configurations II and III the modules were kept in their position on the panels and the backs were enclosed as shown in figure 7 .

\section{Environmenta] Measurements}

The wind and solar measurement instruments used are shown in figure 8. The wind-measuring instruments were installed at approximately the height of the modules. Wind velocity was measured by a commercial three-cup sensor having a small direct-current generator to provide electrical output. Wind direction was measured in $45^{\circ}$ segments, straddling north, northeast, east, southeast, etc. Total solar radiation was measured by an Eppley pyranometer installed at the same inclination and height as the modules. The thermocouple measuring the ambient temperature was embedded in a solder mass and suspended in a shielded vented structure (fig. 9) that was located in the shadow of one of the frames (fig. 10).

\section{Data Recording}

Data were recorded digitally and by a light-beam oscillograph. The following parameters were recorded by both instruments using the same sensor: total solar radiation, ambient temperature, instantaneous and average wind velocities, and wind direction.

Testing proceeded during the relatively clear (cloudless) periods of the day. Data obtained during these periods - even when they lasted a matter of hours rather than a total day - were used in plotting the graphs. The data that were plotted were those taken for average wind velocities of $2.2 \mathrm{~m} / \mathrm{s}$ or 
less. During data taking the oscillograph recorded the traces continuously and the digital system took a datum point every 2 min.

The averaging of wind velocity was based on the wind's thermal effect on the module mass - and on the cell temperature. A time constant calculation was performed on the module with the least mass - type $W$. The time constant was based on 63.2 percent of the change and was calculated to be $40 \mathrm{~s}$. The other modules, with their greater mass, have greater capacities for averaging. This value was incorporated into the data-recording circuit by means of an electronic filter.

\section{RESULTS AND DISCUSSION}

Selected digital data for configurations I, II, and III used for plotting the correlation graphs were based on an attempt to meet the NCCT procedure constraints, such as (1) wind velocity within prescribed values $(0.25$ to $1.75 \mathrm{~m} / \mathrm{s}$ ), (2) steady values of solar radiation, and (3) a southerly wind direction. The oscillograph traces were used to verify these considerations. For wind velocities and ambient temperatures different from the nominal terrestrial environment (NTE) conditions, correction factors shown in the appendix were used. The wind velocity constraint of $1.75 \mathrm{~m} / \mathrm{s}$ was difficult to obtain and therefore, average wind velocity values up to $2 \mathrm{~m} / \mathrm{s}$ were used. An average cell temperature was determined from the values of the two cell temperature measurements.

\section{Configuration I}

Four different modules were tested simultaneously, and this afforded the opportunity to compare the thermal response of each module to a common set of environmental conditions. The data show a scatter that generally is within the limits experienced by JPL. Of particular interest are the four data points taken on September 22, 1977, at the $100-\mathrm{mW} / \mathrm{cm}^{2}$ level in figure 11 (a) to (d). The type $Y$ and $Z$ modules show an alignment of the four points but in a direction that is divergent from a line that could be drawn through the other points. Types $w$ and $x$, on the other hand, show more of a clustering of points closer to a line drawn through those other points.

The lines were drawn by "eye" with an intercept passing through the origin. The lines favored the data taken on September 8 - the day providing the most continuous clear-sky condition. The curve, in effect, is an "average line" that is weighted by engineering judgment.

Figures $11(\mathrm{e})$ to $(\mathrm{h})$ present the data obtained in the afternoon. Comparing the morning curve with the afternoon curve for any one module shows virtually a coincident line. A shift had been noted by JP between morning and afternoon data - hence the request to plot the sets separately. They attributed the cause of the shift to the difference in air conditions (temperature and/or wind direction) between morning and afternoon. For the test in the Lewis STF the average ambient temperature for the readings used in the plots ranged from $19.2^{\circ} \mathrm{C}\left(10: 44\right.$ a.m., Sept. 22) to $27.7^{\circ} \mathrm{C}(1: 54 \mathrm{p.m}$., Sept. 8). This range of air temperature appears to be sufficiently smali so as to eliminate differentiating between the morning and afternoon data. There was also no difference in the prevailing winds between morning and afternoon. Using data points where the wind velocity reached an average value of $5 \mathrm{mph}$ did not produce a greater scattering of points or a greater deviation from the faired curve as long as the correction factor was used. The reason why the morning and afternoon data showed a shift at JPL but showed no difference at Lewis is 
not readily explainable. The contrast suggests that the phenomenon may be more than a matter of air temperature or direction - perhaps a factor dependent on site location. Further investigation was not pursued in this report.

NOCT was obtained by determining the single value of temperature difference (cell minus ambient) at a solar radiation of $80 \mathrm{~mW} / \mathrm{cm}^{2}$ from the curves and adding $20^{\circ} \mathrm{C}$ (appendix). The results and the comparison to JPL values are as follows:

$\begin{array}{ccc}\text { Module } & \begin{array}{c}\text { Lewis }{ }^{\circ} \mathrm{NOCT}, \\ \mathrm{Y}\end{array} & \mathrm{JPL}{ }_{{ }_{\mathrm{C}}}^{\mathrm{NOCT}}, \\ \mathrm{Z} & 46 & 47.1 \\ \mathrm{~W} & 45 & 46.0 \\ \mathrm{X} & 41 & 41.1 \\ & 401 / 2 & 42.9\end{array}$

The difference in NOCT between Lewis and JPL is 1 degree $C$ or less for the first three modules and $21 / 2$ degrees $C$ for the type $X$ module. The agreement can be considered excellent.

\section{Configurations II and III}

Plotting the temperature and solar radiation data for configurations II and III results in the plots of figure 12. The two distinct features for configurations II and III are the differences between morning and afternoon results and the higher temperatures encountered with the back enclosure. The enclosure with insulation has, as expected, a higher cell temperature than the enclosure without insulation. The morning and afternoon data of figure 12 are for a clear day. For configuration III for a given value of solar radiation, the afternoon cell temperatures are higher than the morning cell temperatures. This difference is due to a thermal lag created by the heat storage in the enclosure, which results in a long thermal time constant, unlike the short time constant of less than a minute for configuration I. The data of figure 12 indicate that in any design of a photovoltaic system, stagnant air pockets should be avoided. The results of such air pockets (as simulated by the enclosure) is high temperatures, which decrease power. The effect of higher afternoon cell temperatures is very pronounced for configuration III, where the thermal lag effects are greater because of the enclosure insulation. For configuration II at the higher value of solar radiation, lower cell temperatures were recorded in the afternoon ( $f$ ig. 12). The difference in the two curves is probably due to wind and thermal lag effects.

Inner back surface temperatures of the enclosure are correlated in figure 13. Figure 13 shows greater temperature differences for the enclosure with insulation and an increase in temperature difference with solar radiation. An unusual result that is observed from a comparison of figure 12(b) and the configuration III correlation curve for type $W$ in figure 13 is that, for a given value of solar radiation and ambient temperature, the enclosure back surface temperature is higher than the cell temperature. The reason is that the clear plastic cell encapsulant of type $W$ allows sunlight to pass through to the enclosure back through the portion of the encapsulant between solar cells. The effect is for the back surface of the enclosure to receive thermal energy in addition to that received from the cells by convection and radiation. 
Data used to determine the NOCT values for configurations II and III, corrected as appropriate, are plotted in figure 12. Reading the cell temperature difference at $80 \mathrm{~mW} / \mathrm{cm}^{2}$ and adding $20^{\circ} \mathrm{C}$ yielded the NOCT values listed in table II. Table II includes the NOCT values for the JPL standard test (configuration I). The afternoon NOCT data for configuration II are not given because the wind velocities were higher than $5 \mathrm{~m} / \mathrm{s}$.

Since photovoltaic power decreases $1 / 2$ percent per degree increase in temperature, the effect of an enclosure and enclosure insulation (morningafternoon) for a type $Y$ module is a power decrease of 4.5 percent (configuration II, a.m.), 9.5 percent (configuration III, a.m.), 17.5 percent (configuration III, p.m.), respectively, from the power value of configuration I.

\section{CONCLUSIONS}

The nominal operating cell temperature (NOCT) values for the unenclosed modules obtained at the Lewis Research Center showed close agreement to the values obtained at JPL. Three module designs differed by $1.1^{\circ} \mathrm{C}$ or less, and the fourth design by $21 / 2^{\circ} \mathrm{C}$. The NOCT procedure has thus been verified for open modules at a location other than JPL.

The data collected at Lewis included those obtained at wind velocities higher than the limit set by JPL. Where JPL stipulated a maximum wind velocity of $1 \mathrm{~m} / \mathrm{s}(21 / 2 \mathrm{mph})$, Lewis data were obtained at wind velocities of up to $2.2 \mathrm{~m} / \mathrm{s}(5 \mathrm{mph})$. No loss of accuracy was experienced.

Photovoltaic cells of modules with the back surface enclosed experienced continually changing temperatures during testing. The non-steady-state condition was due to the long time constant associated with natural convection and the thermal mass within the enclosure volume and made repeatable results highly unlikely. The NOCT procedure, as presently simulated, is not suited for modules with the back surface enclosed.

The enclosed modules experienced higher cell temperatures than the open modules. The enclosed design therefore may be expected to operate at a lower power rating than the same module operating without an enclosure. On one insulated enclosure module design, the cell reached a temperature that, when translated to module power output, would mean a 17.5 percent loss in performance as compared with the same module without an enclosure. 
APPENDIX - DETERMINATION OF NOMINAL OPERATING CELL TEMPERATURE

This appendix describes the approved procedure for determining the nominal operating cell temperatures of solar cell modules by using natural sunlight testing.

\section{Purpose}

The purpose of this testing is to acquire sufficient data to allow an accurate determination of the nominal operating cell temperatures of the solar cells of a terrestrial solar array module.

By definition, the nominal operating cell temperature is the module cell temperature under operating conditions in the nominal terrestrial environment (NTE), which is defined as

Insolation, $\mathrm{mW} / \mathrm{cm}^{2}$. . . . . . . . . . . . . . . 80

Air temperature, ${ }^{\circ} \mathrm{C}$. . . . . . . . . . . . . . . . . . 20

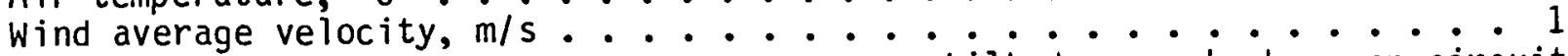
Mounting.............. tilted, open back, open circuit

The NOCT test procedure is based on gathering actual measured cell temperature data by means of thermocouples attached directly to the cells of interest, for a range of environmental conditions similar to the NTE. The data are then presented in a way that allows accurate and repeatable interpolation of the NOCT temperature.

\section{Determination of NOCT}

The temperature of the solar cell $T_{\text {cell }}$ is primarily a function of the air temperature $T_{\text {air }}$, the average wind velocity $V$, and the total solar insolation $L$ impinging on the active side of the solar array module. The approach for determining NOCT is based on the fact that the temperature difference $T_{c e l 1-T_{\text {air }}}$ is largely independent of air temperature and is essentially linearly proportional to the insolation level. Analyses indicate that the linear assumption is quite good for insolation levels greater than about $40 \mathrm{~mW} / \mathrm{cm}^{2}$. The procedure calls for plotting $T_{\text {cel }}$ l $-T_{\text {air }}$ against the insolation level for a period when wind conditions are favorable. The NOCT value is then determined by adding $T_{\text {air }}=20^{\circ} \mathrm{C}$ to the value of $T_{\text {cell }}$ - Tair interpolated for the NTE insolation level of $80 \mathrm{~mW} / \mathrm{cm}^{2}$, that is, NOCT $=\left(T_{\text {cel }}-T_{\text {air }}\right)_{N T E}+20^{\circ} \mathrm{C}$.

The plot of Tcell-Tair versus $L$ shall be determined by conducting a minimum of two field tests in which the module being characterized is tested under terrestrial environmental conditions approximating the NTE in accordance with the testing guidelines that follow. Each test shall consist of acquiring a semicontinuous record of $T_{\text {cell }}-T_{\text {air }}$ over a 1- or 2-day period, together with other measurements as required to characterize the terrestrial environment during the testing period. Acceptable data shall consist of measurements made when the average wind velocity is $1 \mathrm{~m} / \mathrm{s} \pm 0.75 \mathrm{~m} / \mathrm{s}$ and with gusts less than $4 \mathrm{~m} / \mathrm{s}$ for a period of 5 min prior to the time of measurement. Local air temperature during the test period shall be 20 C 15 C. Using only acceptable data as so defined, a plot shall be constructed from a set of measurements made either before or after solar noon 
that defines the relationship between ${ }^{1} T_{\text {cell }}-\mathrm{T}_{\mathrm{air}}$ and the solar insolation level for $L \geq 40 \mathrm{~mW} / \mathrm{cm}^{2}$.

When $T_{\text {cell }}-\mathrm{T}_{\text {air }}$ is plotted as a function of $L$ for average wind velocities less than $1.75 \mathrm{~m} / \mathrm{s}$, results similar to those shown in figure 14 are obtained. For the data shown the local air temperature was $15.6^{\circ} \mathrm{C} \pm 4.5^{\circ} \mathrm{C}$ and the wind velocity varied from zero to less than $4 \mathrm{~m} / \mathrm{s}$ with an average of $1 \mathrm{~m} / \mathrm{s}$. Using the plot of $T_{\text {ce }} 11-T_{\text {air }}$ versus $L$, the value of Tce11- Tair at NTE is determined by interpolating the average value of $T_{\text {cell- }}$ - Tair for $L=80 \mathrm{~mW} / \mathrm{cm}^{2}$. Using the data in figure 14 as an example, Tcell-Tair at NTE is determined to be $22.2^{\circ} \mathrm{C}$. The preliminary value of NOCT is thus $22.2^{\circ} \mathrm{C}+20^{\circ} \mathrm{C}=42.2^{\circ} \mathrm{C}$.

\section{Air Temperature and Wind Correction}

A correction factor to the preliminary NOCT for average air temperature and wind velocity is determined from figure 15 . This value is added to the preliminary NOCT and corrects the data to $20^{\circ} \mathrm{C}$ and $1 \mathrm{~m} / \mathrm{s}$. The average temperature and wind velocity for the test period are denoted by $T_{a i r}$ and $V$. For the test data shown in figure $14, V$ was $1 \mathrm{~m} / \mathrm{s}$ and $T_{\text {air }}$ was $15.6^{\circ} \mathrm{C}$. From figure 15 the correction factor is $0^{\circ} \mathrm{C}$. The NOCT is therefore $42.2^{\circ} \mathrm{C}$.

\section{Test Geometry}

Tilt angle. - The plane of the module shall be positioned so that it is normat to the Sun $\left( \pm 5^{\circ}\right)$ at solar noon.

Height. - The bottom edge of the module shall be $0.6 \mathrm{~m}(2 \mathrm{ft})$ or more above the local horizontal plane or ground level.

Subarray configuration. - The module shall be located in the interior of a $1.2-\mathrm{m}$ by $1.2-\mathrm{m}$ (4-ft by 4-ft) subarray. Black aluminum panels or other modules of the same design shall be used to fill in any remaining open area of the subarray structure. The back of the subarray shall be exposed.

Surrounding area. - There shall be no obstructions to prevent full irradiance of the module from a minimum of $4 \mathrm{hr}$ before solar noon and to $4 \mathrm{hr}$ after solar noon. The ground surrounding the module shall not have a high solar reflectance and shall be flat and/or sloping away from the test fixture. Grass and various types of ground covers, blacktop, and dirt are recommended for the local surrounding area. Buildings having a large solar reflective finish shall not be present in the immediate vicinity. Good engineering judgment shall be exercised to assure that the module, front and back sides, is receiving a minimum of reflected solar energy from the surrounding area.

1 The two sets of measurements can be combined into a single set, provided the average air temperature of the two sets does not differ by more than approximately $5^{\circ} \mathrm{C}$. If the average air temperature is significantly different, the resulting effect appears as an increase in the scatter of the plotted data. As a result the data will be more difficult to fit, and a less accurate result is possible. 
Wind direction. - The wind shall not be predominantly from due east or from due west; flow parallel to the plane of the array is not acceptable and can result in a lower than typical operating cell temperature.

Module electric load. - Data shall be obtained for a module open-circuit condition corresponding to zero electric power output.

\section{Test Equipment}

Pyranometer. - The total solar irradiance on the active side of the module shall be measured by a pyranometer mounted on the plane of the module and within $0.3 \mathrm{~m}(1 \mathrm{ft})$ of the array. The pyranometer used shall have a traceable annual calibration to a recognized standard instrument and shall be either (1) a temperature-compensated unit that has less than \pm 1 percent deviation in sensitivity over the range $-20^{\circ} \mathrm{C}$ to $+40^{\circ} \mathrm{C}$ or (2) a unit that incorporates a temperature sensor and has a sensitivity-temperature correction supplied with its calibration.

Wind measurement. - Both the wind direction and wind velocity shall be measured at the approximate height of the module and as near to the module as feasible.

Air temperature. - The local air temperature shall be measured at the approximate height of the module. The measurement shall be made in the shadow of the module and shall be accurate to $\pm 1^{\circ} \mathrm{C}$. (Note: An average local air temperature is desired. This is obtained satisfactorily by increasing the thermal mass of the thermocouple by imbedding the thermocouple in a solder sphere of approximately $0.64-\mathrm{cm}$ (1/4-in.) diameter.) The thermocouple must be appropriately shielded and vented.

Cell temperature. - The temperature of at least two representative interior solar cells shati be measured to $\pm 1^{\circ} \mathrm{C}$. Thermocouples shall be 36 gage and shall be soft-soldered directly to the back of the cell.

Substrate surface temperature. - The exterior temperature of the rear of the solar module shall be measured to $\pm 1^{\circ} \mathrm{C}$ beneath a representative cell and when practical beneath a representative space between cells. Thermocouples shall be 26 gage and shall be bonded down with 57-C epoxy or the equivalent.

\section{Data Recording}

All data shall be printed out approximately every 2 min. In addition, solar intensity, wind velocity, wind direction, and air temperature shall be continuously recorded.

\section{Cleaning}

The active side of the solar cell module and the pyranometer bulb shall be cleaned before the start of each test. Dirt shall not be allowed to build up. Cleaning with a mild soap solution followed by a rinse with distilled water has proven to be effective.

\section{Equipment Calibration} test.

A calibration check shall be made of all the equipment before starting the 


\section{Test Description Page}

The test description page illustrated in figure 16 shall be completed before starting the test.

\section{Automation}

Once data collection is started, the data may be collected automatically. However, the equipment shall be checked once every hour. 


\section{REFERENCES}

1. User Handbook for Block II Silicon Solar Cell Modules. JPL-5101-36, Jet Propulsion Lab., Oct. 1977.

2. Thermal Performance Testing and Analysis of Photovoltaic Modules in Natural Sunlight. JPL-5101-31, Jet Propulsion Lab., July 1977.

TABLE 1. - MODULE CHARACTERISTICS

\begin{tabular}{|l|r|r|r|r|}
\hline \multirow{2}{*}{ Characteristics } & \multicolumn{4}{|c|}{ Module } \\
\cline { 2 - 5 } & \multicolumn{1}{|c|}{$\mathrm{x}$} & \multicolumn{1}{|c|}{$\mathrm{r}$} & \multicolumn{1}{c|}{$\mathrm{Z}$} \\
\hline Overall dimensions, cm (in.): & & & & \\
Length & $55.9(22.0)$ & $58.2(22.9)$ & $116.8(46.0)$ & $116.8(46.0)$ \\
Width & $29.0(11.4)$ & $58.2(22.9)$ & $38.9(15.3)$ & $38.9(15.3)$ \\
Height & $4.6(1.8)$ & $4.6(1.8)$ & $4.8(1.9)$ & $3.6(1.4)$ \\
Weight, kg (1b) & $1.5(3.3)$ & $4.1(9.0)$ & $7.6(16.7)$ & $6.1(13.5)$ \\
Number of cells & $5.6(2.2)$ & $7.6(3)$ & $10.2(4)$ & $5.1(2)$ \\
Cell diameter, cm (in.) & $5.6(2.2)$ & 40 \\
\hline
\end{tabular}

TABLE II. - NOMINAL OPERATING CELL TEMPERATURE

VALUES FOR THREE CONFIGURATIONS TESTED

\begin{tabular}{|c|c|c|c|c|}
\hline \multirow{3}{*}{ Module } & \multicolumn{4}{|c|}{ Conf iguration } \\
\cline { 2 - 5 } & I & II & \multicolumn{2}{|c|}{ III } \\
\cline { 2 - 5 } & $\begin{array}{c}\text { Clear dry, } \\
\text { morning and } \\
\text { afternoon }\end{array}$ & $\begin{array}{c}\text { Clear day, } \\
\text { morning }\end{array}$ & \multicolumn{2}{|c|}{ Clear day } \\
\cline { 2 - 5 } & \multicolumn{4}{|c|}{ NOCT value } \\
\hline Y & 46 & 55 & 65 & 81 \\
Z & 45 & 48 & 58 & 75 \\
W & 41 & 45 & 54 & 67 \\
$X$ & 41 & 47 & 51 & 62 \\
\hline
\end{tabular}




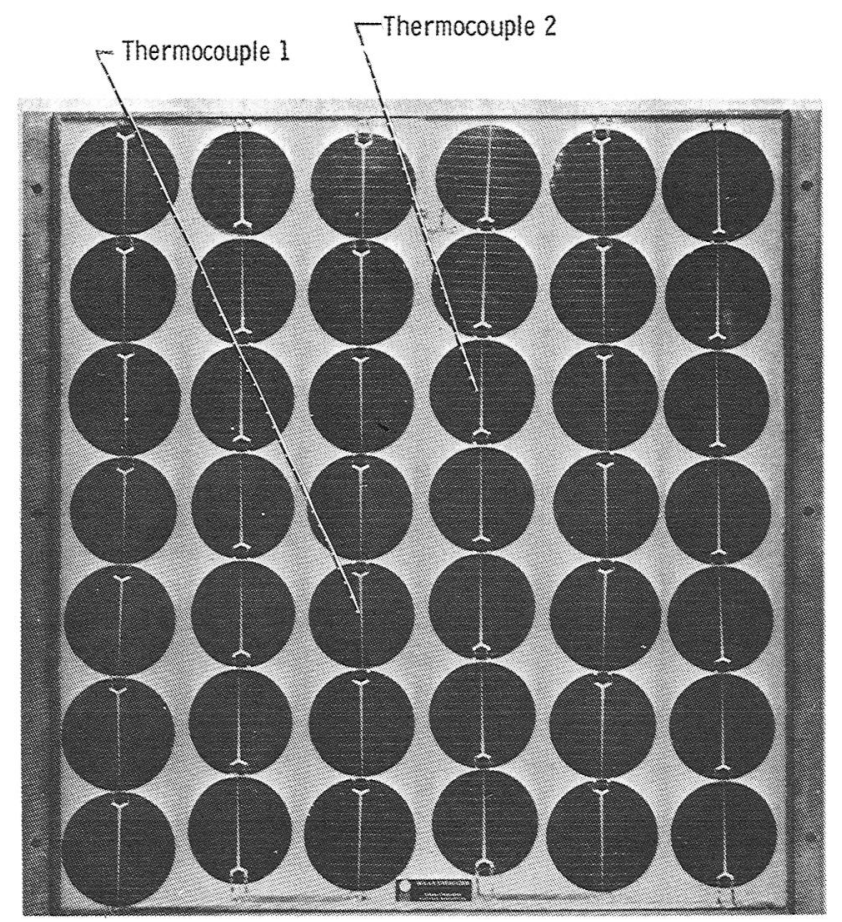

Figure 1. - Thermocouple locations on type Y module.

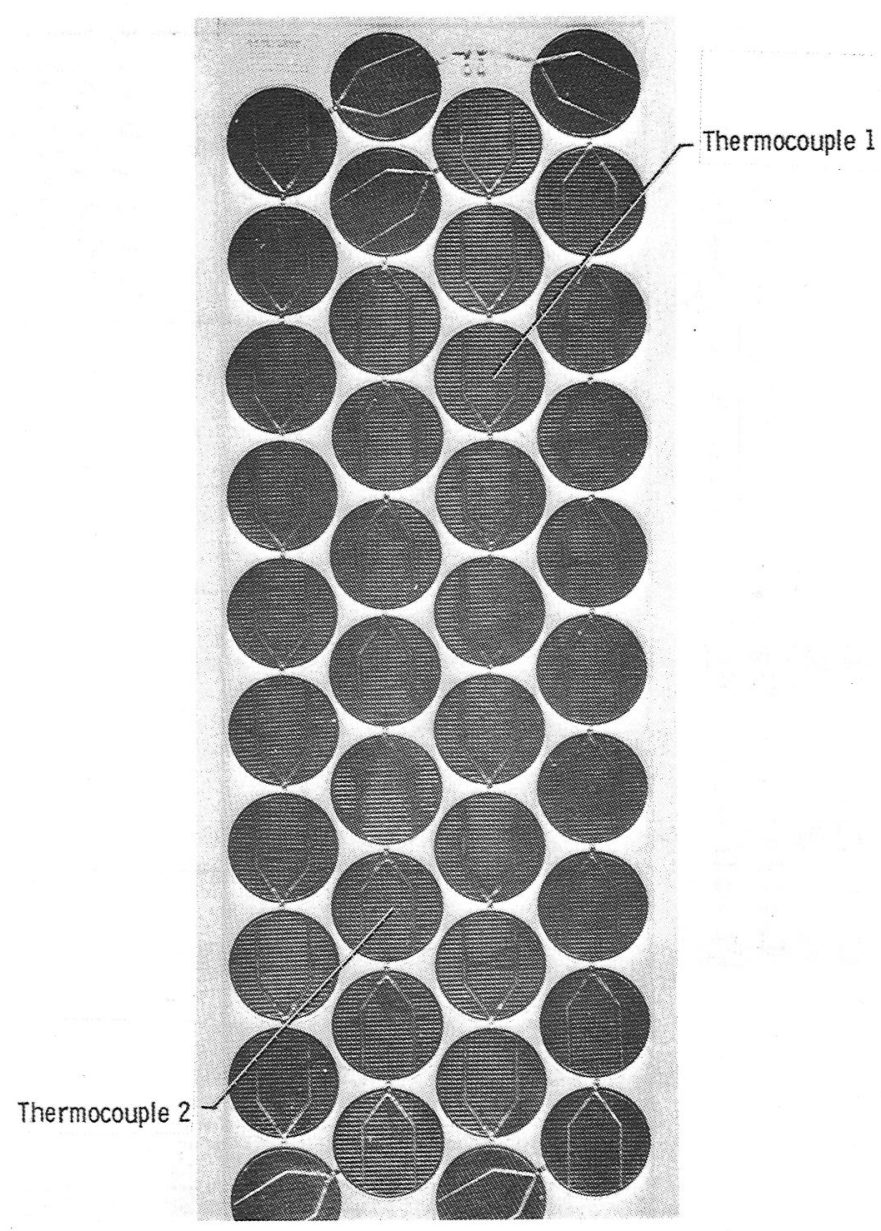

Figure 2 - Thermocouple locations on type Z module. 


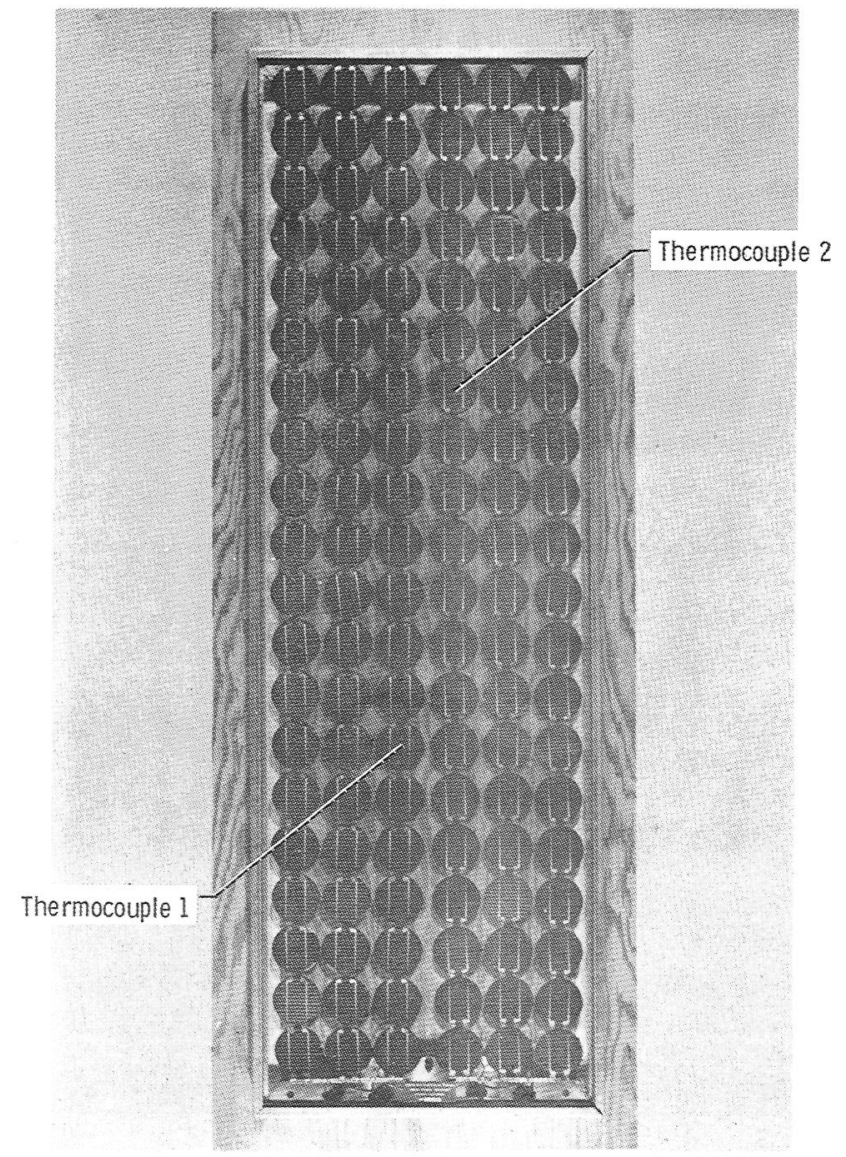

Figure 3. - Thermocouple locations on type W module.

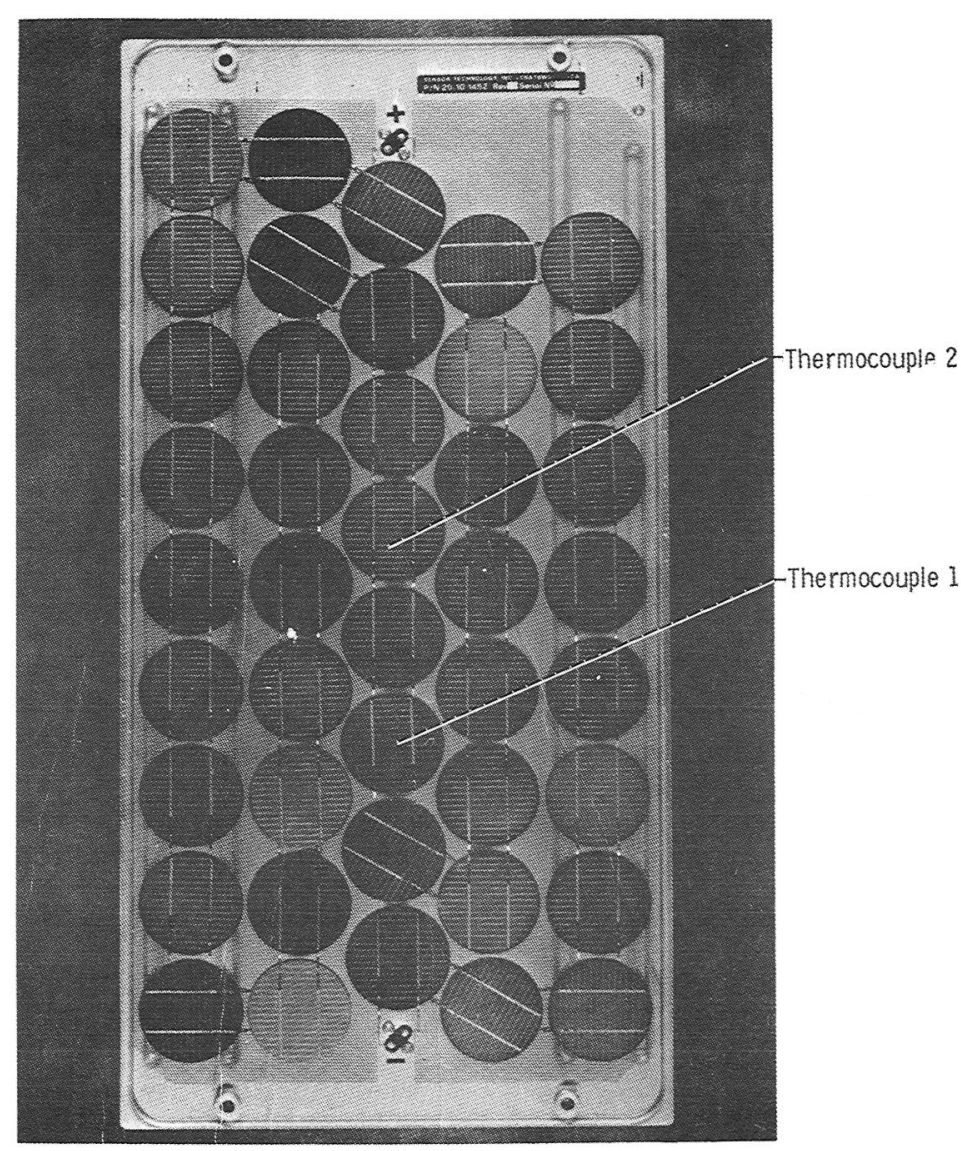

Figure 4. - Thermocouple locations on type X module. 


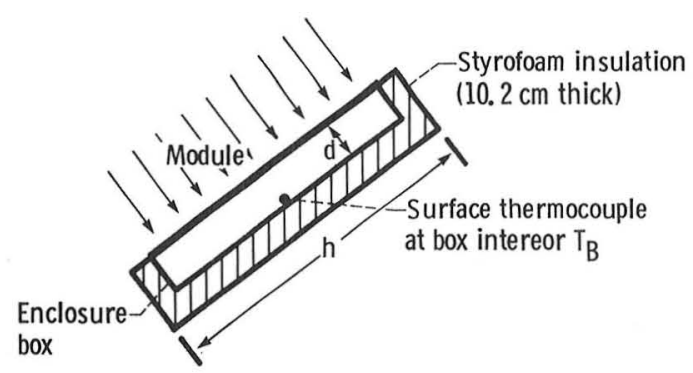

\begin{tabular}{|c|c|c|c|}
\hline \multirow{2}{*}{$\begin{array}{c}\text { Module } \\
\text { type }\end{array}$} & \multicolumn{3}{|c|}{ Enclosure interior dimensions, cm } \\
\cline { 2 - 4 } & Width & $\begin{array}{c}\text { Height, } \\
\text { h }\end{array}$ & $\begin{array}{c}\text { Depth, } \\
\text { d }\end{array}$ \\
\hline Y & 52.1 & 61.0 & 4.8 \\
Z & 35.6 & 108.0 & 4.5 \\
W & 38.1 & 109.2 & 4.7 \\
X & 32.4 & 51.8 & 5.2 \\
\hline
\end{tabular}

Configuration I- unenclosed module Configuration II - module plus enclosure box Configuration III - module plus enclosure box insulation

Figure 5. - Schematic of module back surface enclosure (side view).

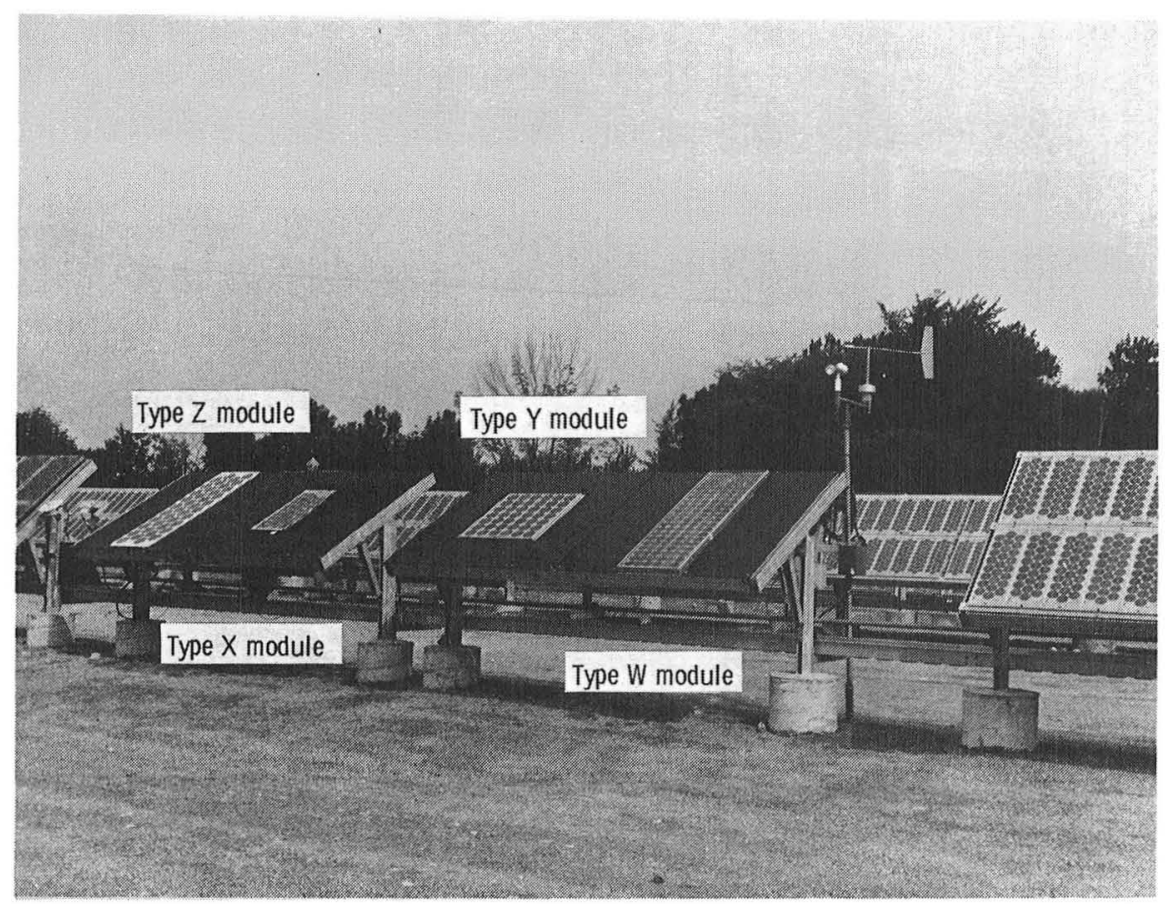

Figure 6. - Unenclosed modules mounted for thermal test (configuration I). 


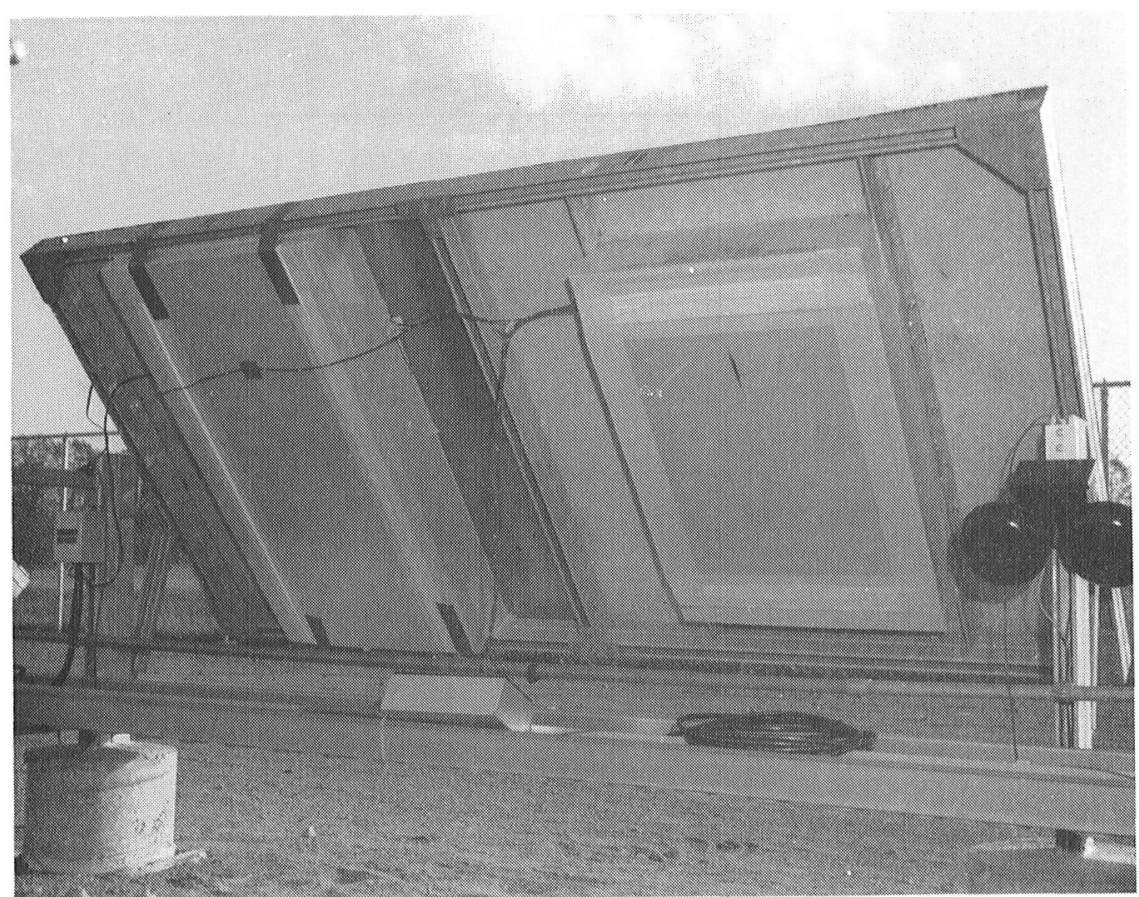

Figure 7. - Inermal test configuration 111 , snowing enclosed back of module.

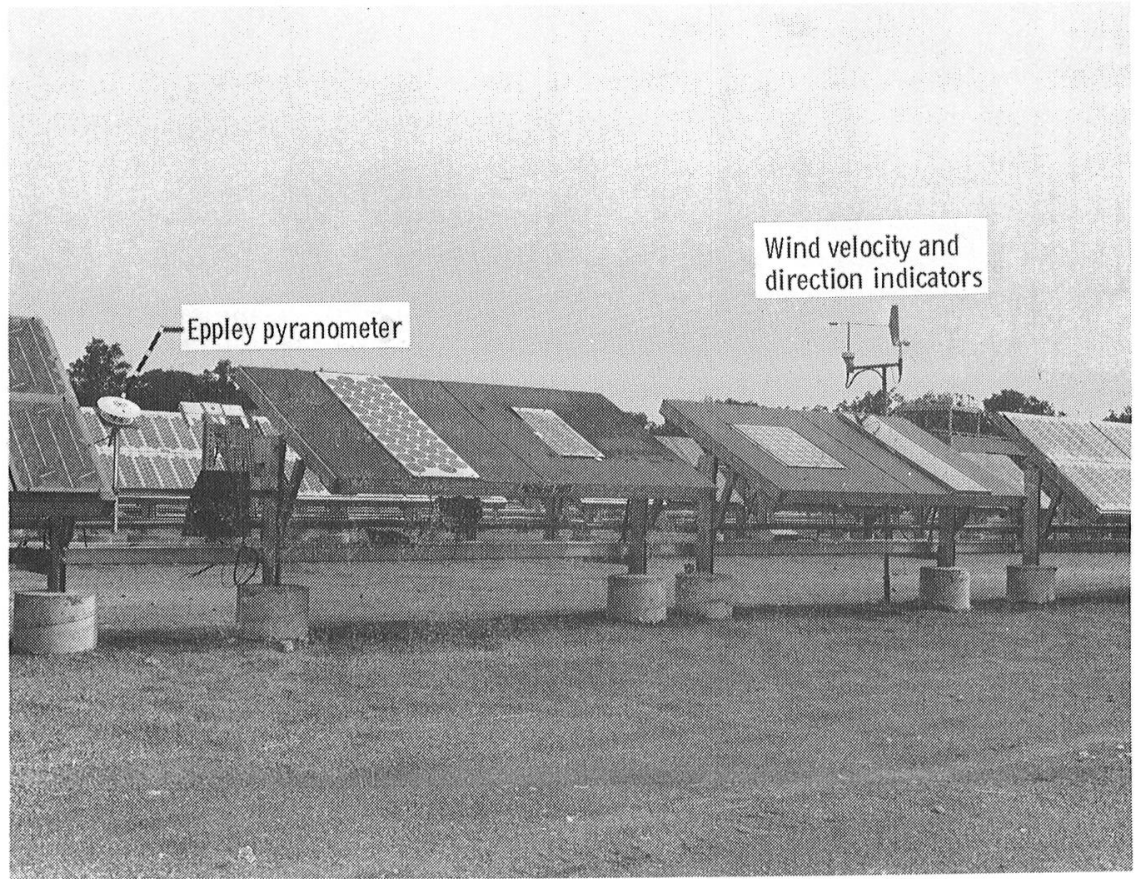

Figure 8. - Solar and wind instrumentation for nominal operating cell-temperature 

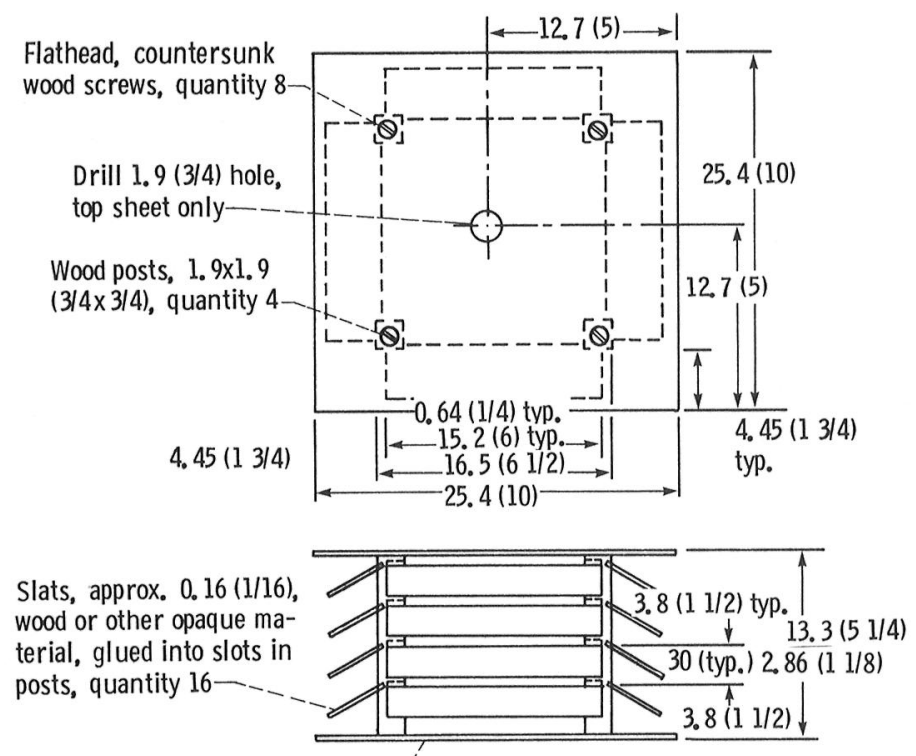

Sheets, approx. $0.32(1 / 8)$ thick

wood or other opaque material,

quantity 2

Figure 9. - Ambient air temperature thermocouple housing. (Dimensions are in centimeters (inches).)

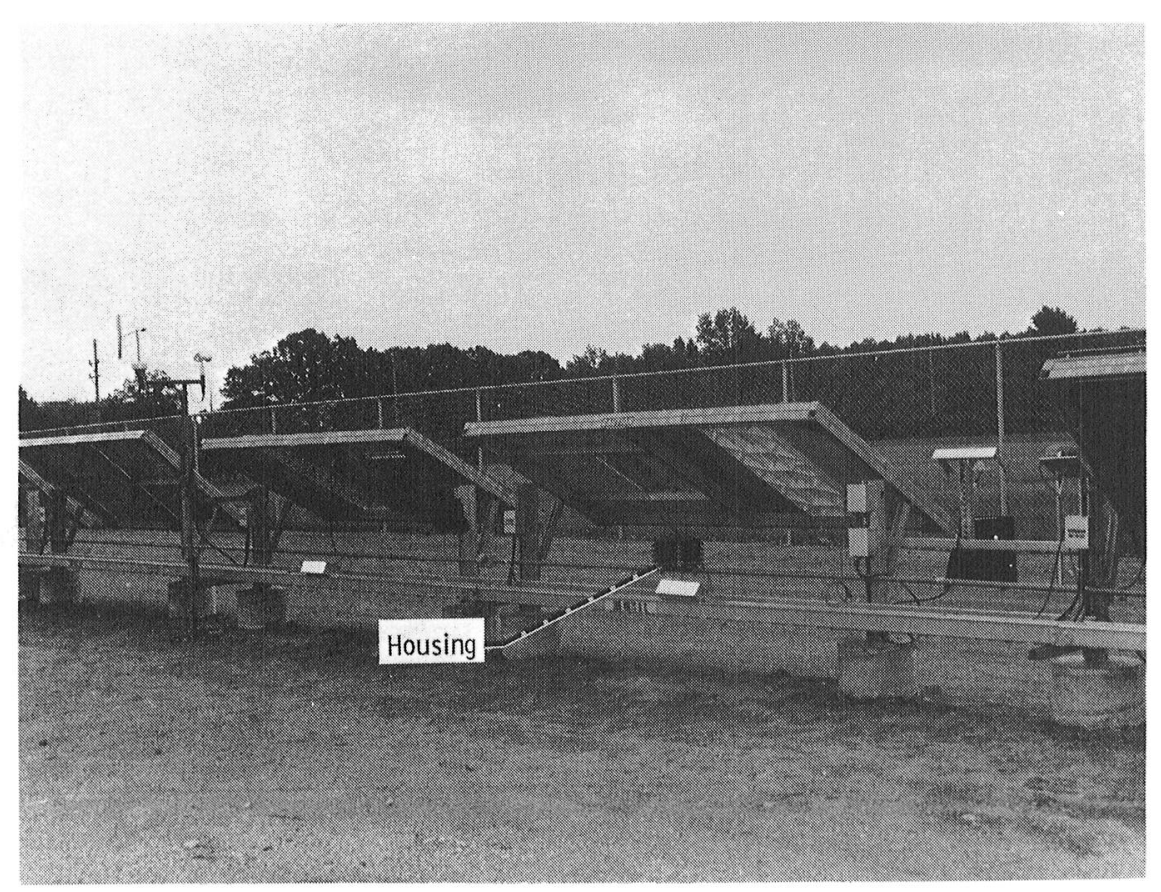

Figure 10. - Mounting of ambient temperature thermocouple housing for test. 
口 9122/77

$\triangle 9123177$

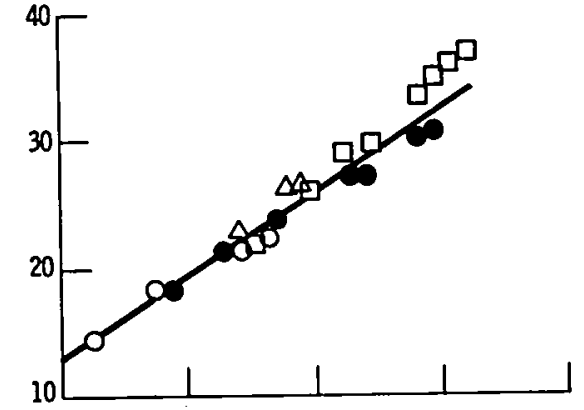

(a) Module type $Y$, morning.

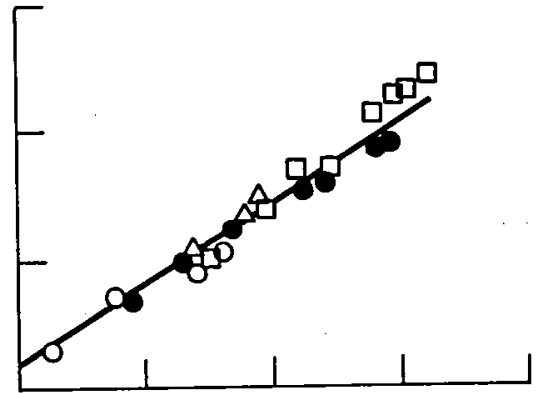

(b) Module type Z, morning.

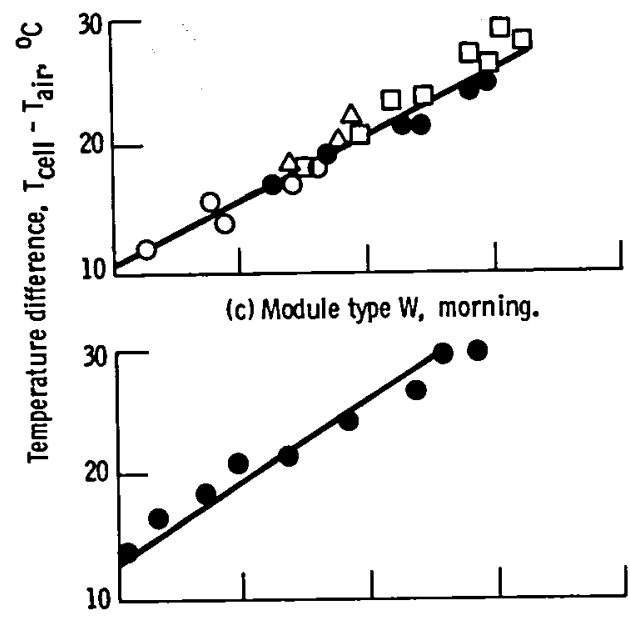

(e) Module type $Y$, afternoon.

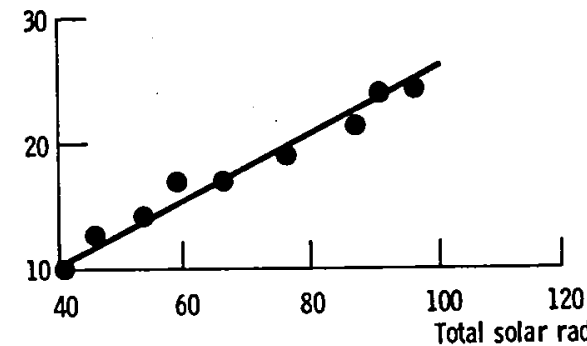

(g) Module type W, afternoon.

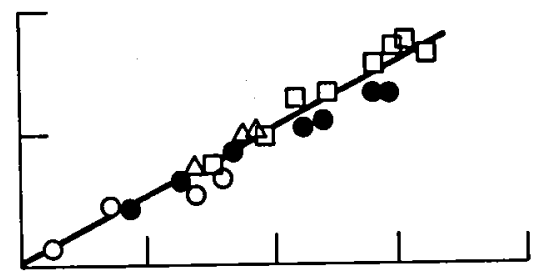

(d) Module type $X$, morning.

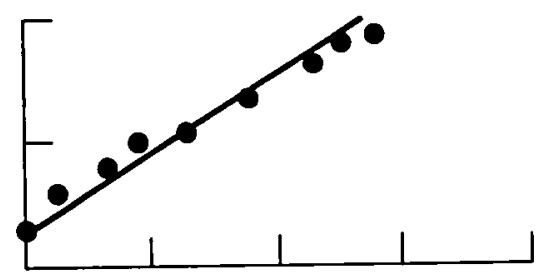

(f) Module type Z, afternoon.

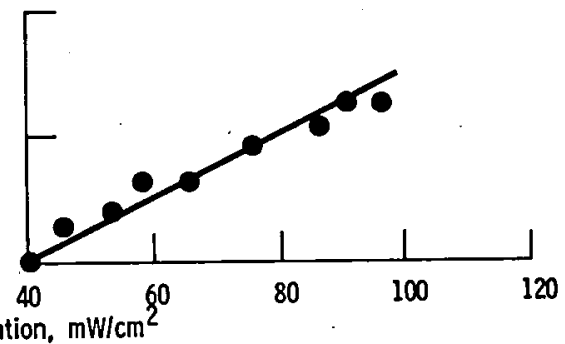

(h) Module type $X$, afternoon.

Figure 11. - Cell temperature - solar radiation correlations for configuration I, morning and afternoon. 


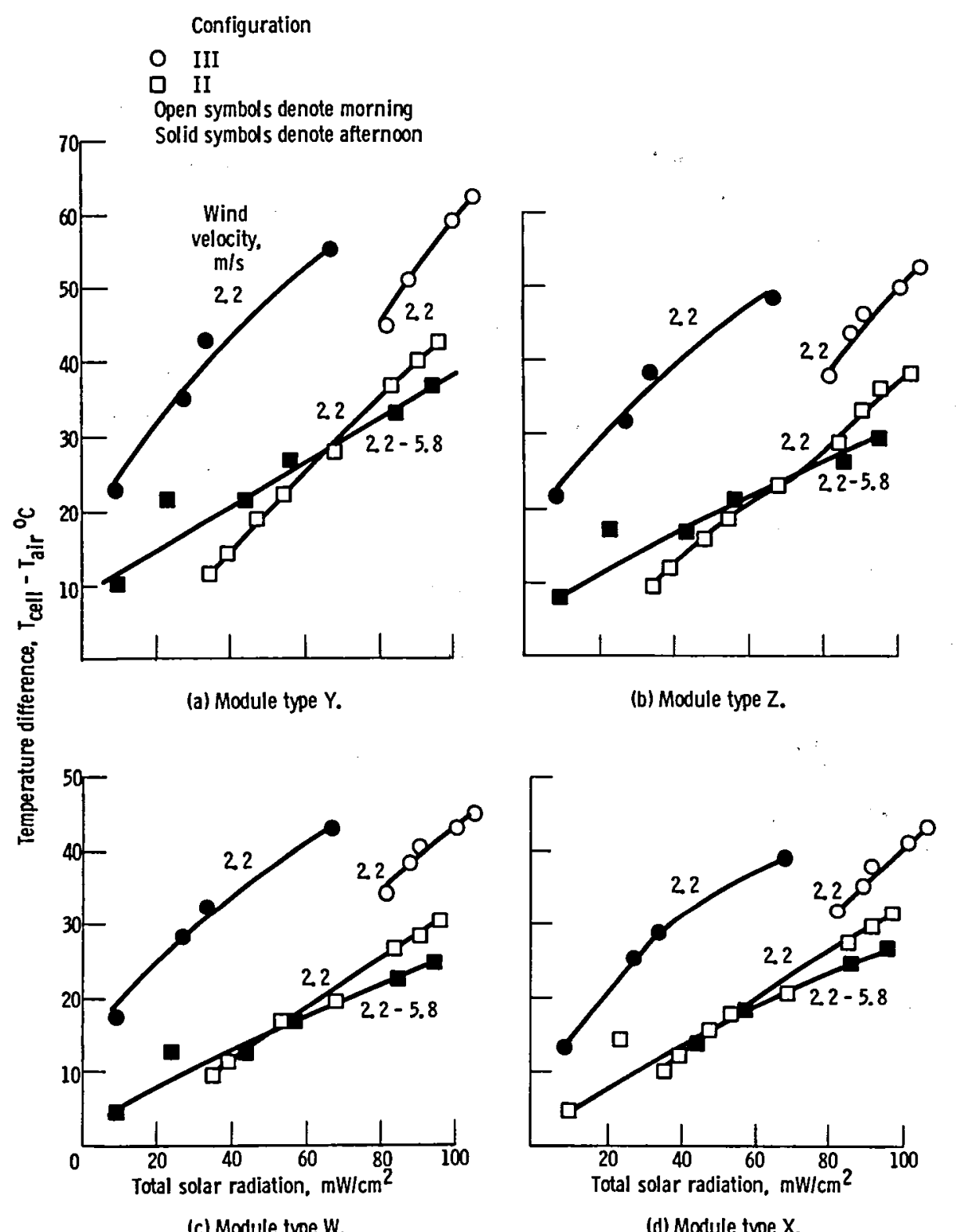

Figure 12 - Cell temperature - solar irradiation correlations for configurations II and IIL morning and afternoon. 

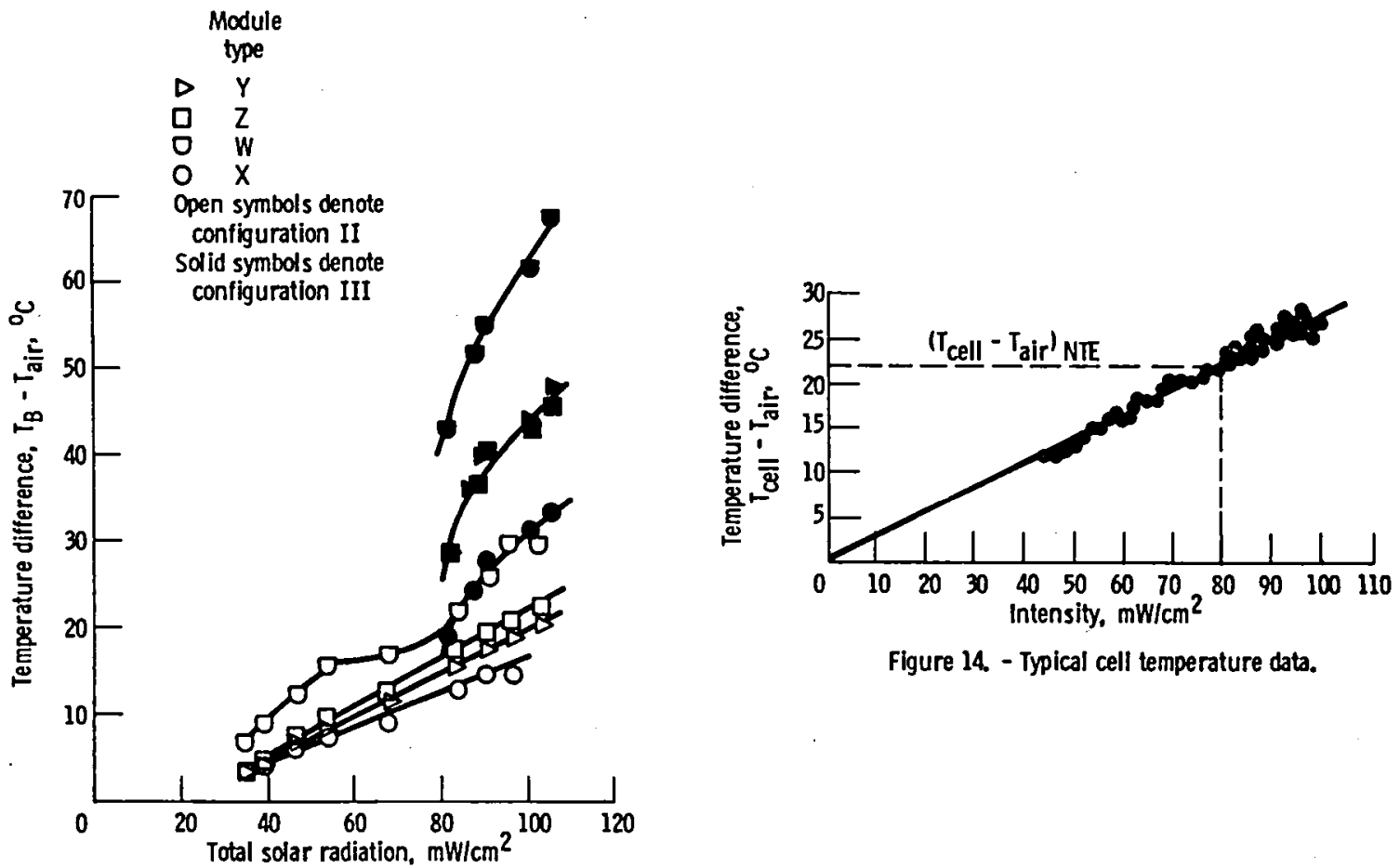

Figure 14. - Typical cell temperature data.

Figure 13. - Enclosure back surface temperature solar radiation correlation for configurations II and IIL.

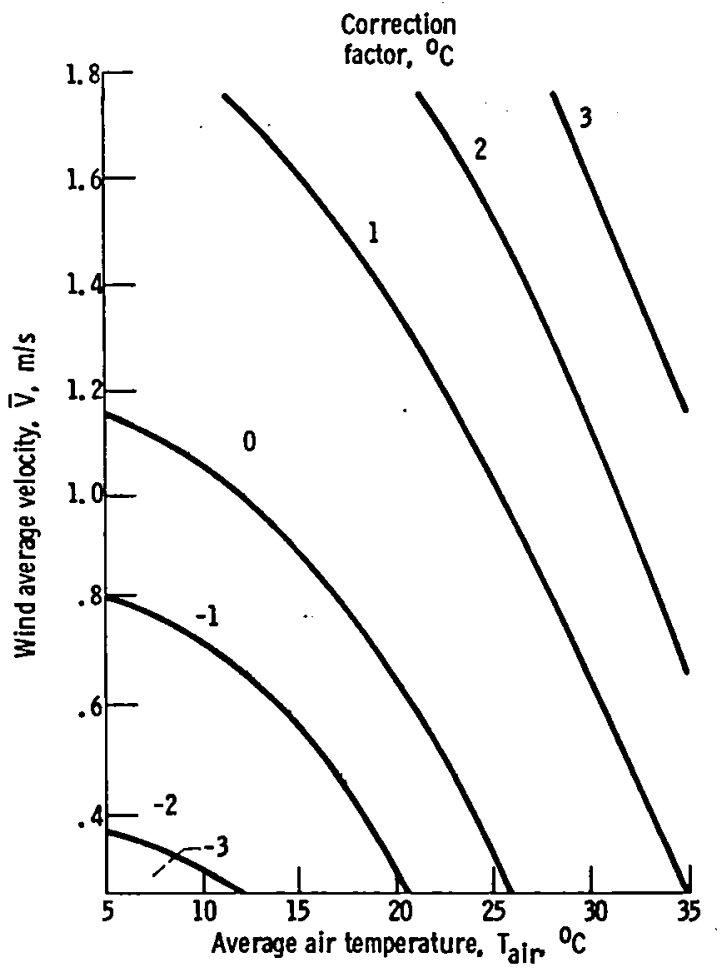

Figure 15. - Nominal operating cell temperature (NOCT) correction factors. 
TEST DESCRIPTION

Title: Natural Sunlight Thermal Performance Test

Article:

Sertal \#

Location:

Latitude:

Elevation:

Date: Solar Noon Optical Air Mass

Cleaning Agent Used:

T11t Angle: Actual Destred

Equipment Calibration Complete

Name Ext.

Comments:

Pigure 16. - Test description page. 


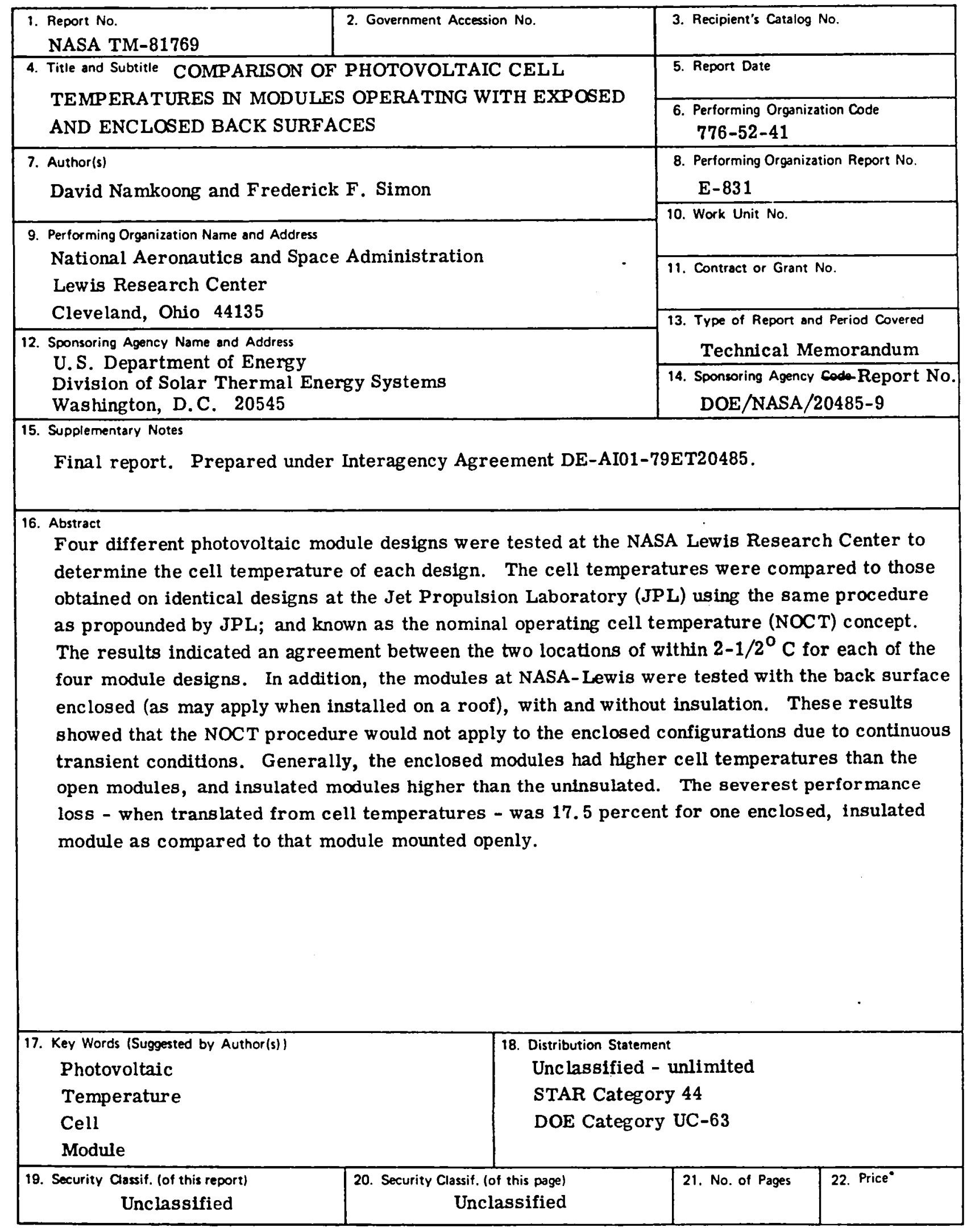

* For sale by the National Technical Information Service, Springfield, Virginia 22161 
